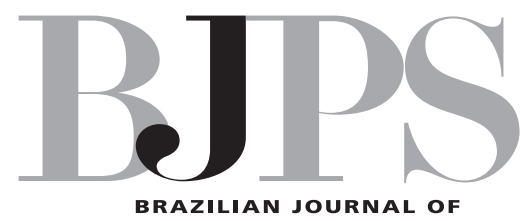

Brazilian Journal of

\title{
Open access, authors' right, and scientific academy duty: an undelayable commitment!
}

Brazilian Journal of Pharmaceutical Sciences, two years after its editorial reformulation, including the adoption of English as its official language, has been nationally and also internationally recognized. For this very reason, new challenges have to be faced and new patterns have to be followed. Nowadays, BJPS is indexed in the most recognized databases, as Web of Science, Scielo, International Pharmaceutical Abstracts, among others. Our responsibility in maintaining the quality level as required by international organs while reaching conditions for a sustainable growing has substantially increased from then on. So, it is interesting to point out some questions to be reflected by national Scientific Editors and by the scientific academy in general. Those questions have been permanently discussed in Editors meetings. We are quite sure that all of us are longing for the proper answers.

One of the questions is about author's right. When the authors submit their manuscripts to evaluation and further publication, they usually give the rights to the journal. This happens towards a democratic access. We think this is the principle that has to be followed!

BJPS is completely engaged in this police of open access. However, this police must be a matter of discussion and this may be extended to all editors, especially those from journals that have been published with public resources. Some important questions arise herein: how often the Brazilian researchers publish in national and open access journals? Is it fair to feed the international journals with papers of excellence and after paying for their access? Why not publishing in national journals? Why the national journals have to fight hard in the search for higher impact indexes if the latter depend on citation of papers of excellence and most of those papers have been published in foreign scientific periodicals?

The problem of public financing of Brazilian journals deserves more attention. According to Ortellado and Machado (2006), the researchers have their researches, generally, supported by public financial agencies. Besides, those agencies have programs of supporting periodicals acquisition, directed to the libraries of universities and institutions of research, and Brazilian journals edition, including those from Scientific Societies and Institutions as well. It is important to emphasize that this support is conditioned to Open or Free Access, in order to provide the full accessibility of the knowledge generated.

Our long time experience of editing the BJPS, formerly Revista de Farmácia e Bioquímica da Universidade de São Paulo, allows us to conclude that only after being indexed (see the Graphs I to IV) by the 


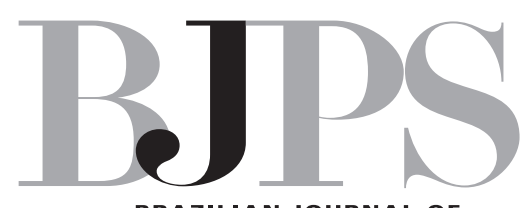

Brazilian Journal of

Pharmaceutical Sciences

Indexing databases early mentioned the number of papers submitted increased, and, consequently, the number of accepted/published and refused papers as well.

This scenario lead us to the conclusion that status quo, I mean, the requirements of scientific performance through the number of indexed papers overrule the preoccupation related to the right of opening access of the generated knowledge. Most of the top publishing companies, which dominate the editorial market of scientific publications and have a rigid police of author's right, are imposing restrictions to the access. It is known that the costs of subscription paid by the public financial organs are very high (Ortellado e Machado, 2006). However, we have to pay for the Science developed here since most of the Brazilian papers have been published in foreign and indexed journals. Meanwhile, we, Brazilian editors, go permanently for the increase in the impact indexes of our journals. Would it be possible to be recognized as NATIONAL divulgation vehicles of the science developed and accessed in the country?

Notwithstanding, it must be emphasized that SciElo (Scientific Eletronic Library Online) represented a great advance to the Brazilian journals visibility through the open access of their papers, minimizing the problem in early discussed, in Brazil. Besides, this indexing database has contributed a lot for improving the quality of the journals through its high pattern requirements of quality.

Unfortunately, the problems discussed herein keep going and the participation of the scientific academy and its commitment with the national publications are urgently needed, otherwise, the future may bring the editors a serious risk of being hostages of big international publishing companies. A question arises in this situation: Should we become hostages of those publishing companies? In this context, Salinas (2010) described the experience of Brazilian Journal of Physics, which is now edited by a foreign publishing company and thus the access has been restricted (Oliveira, 2011). Experiences like this are common among national editors, especially those from developing countries.

The University of Sao Paulo is offering ways of capacitating its researchers in improving their writing in many aspects, including English. Knowledge generation and publication in specialized journals have been highly stimulated in the Institution (Marques, 2011). However, the University also has the responsibility of stimulating and fomenting the diffusion of scientific production of their members since it has a Committee dedicated to support their journals (Comissão de Credenciamento, 2011). Besides, I believe, it is mandatory to give value to their editors and professionals of the editing area. This does not mean to turn our journals endogenic. This can be translated into a way of reaching higher recognition and visibility in the international scenario.

It is important to stress also the necessity of commitment of the universities in general with the review of the actual parameters of national journals classification by those organs responsible to qualify the academic production, mainly those related to graduate course.

Concerning BJPS, increasing the number of manuscript submission is of utmost importance. We need papers of high quality to grow more and more. Our visibility depends not only on the number of submis- 


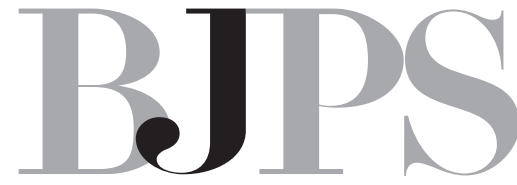

sions but also on the open access we want to keep up, as a matter of democracy in the science environment, as mentioned before. The citations are, then, consequence, as is the higher recognition of the journal as an international vehicle of science divulgation, in this case, pharmaceutical sciences divulgation.

We are pleased to announce that BJPS is now included in the Journal Citation Reports 2010 with an impact index of 0.254 . This beginning leads us to high responsibility, considering the rigid requirements to be indexed in the Web of Science. Any failure can compromise years of working hard. However, we are quite sure that together with the authors, we will succeed, getting higher indexes!

I would like to thank Professor Elizabeth Igne Ferreira, the Scientific Editor of BJPS, and to all the Associated Editors. They have been confident on my work and are always stimulating my initiatives in the executive edition of BJPS.

\section{Leila R. de Carvalho Aranha \\ Executive Editor}

\section{Brazilian Journal of Pharmaceutical Sciences}

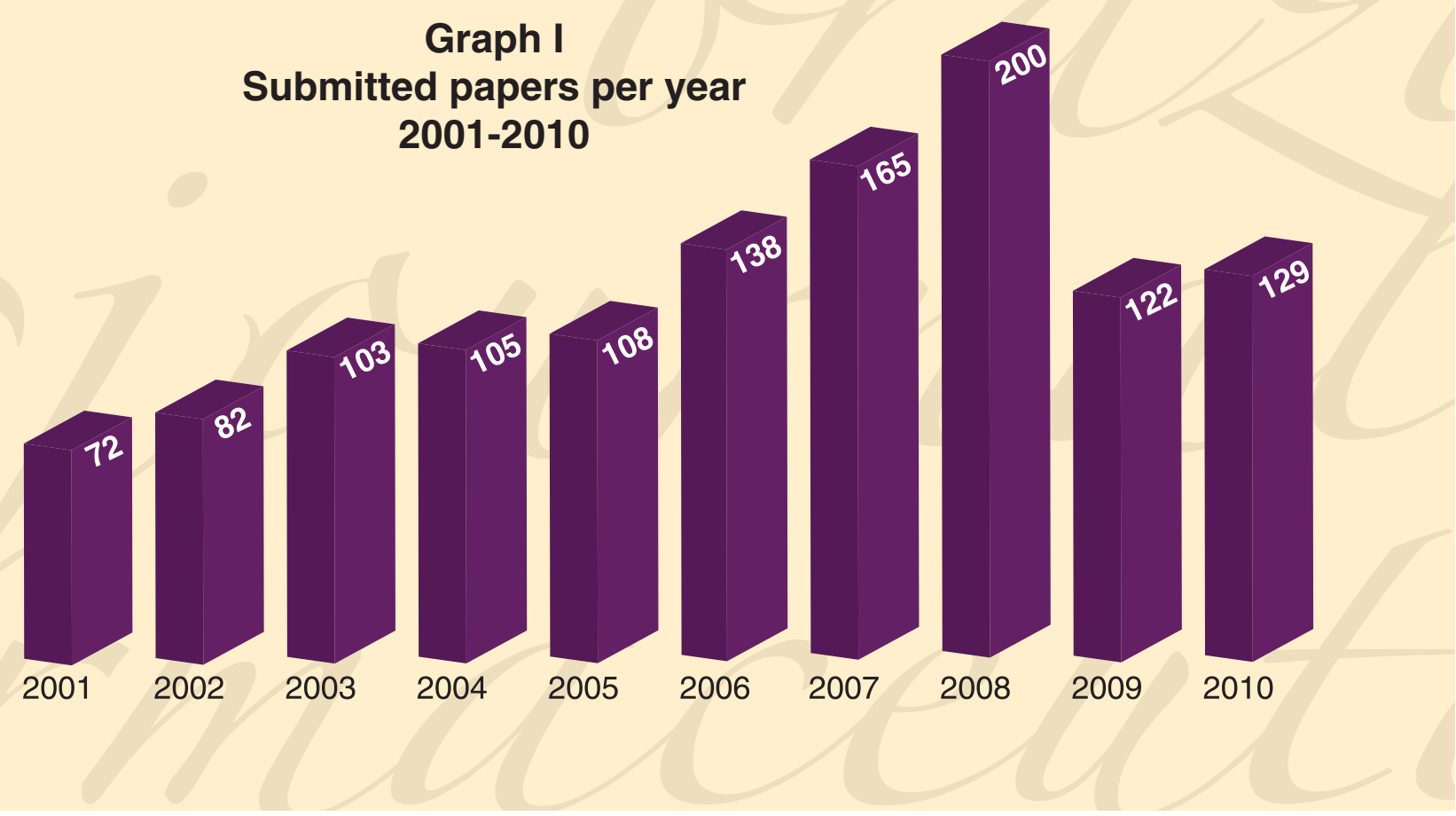




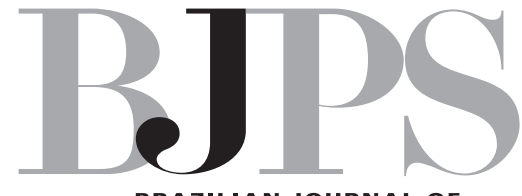

Brazilian Journal of

Graph II

Published papers per year

1993-2010

34

$13 \quad 10 \quad 14 \quad 15 \quad 17 \quad 14$

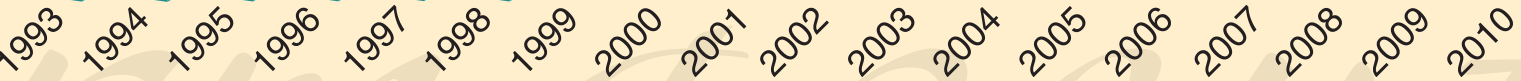

96

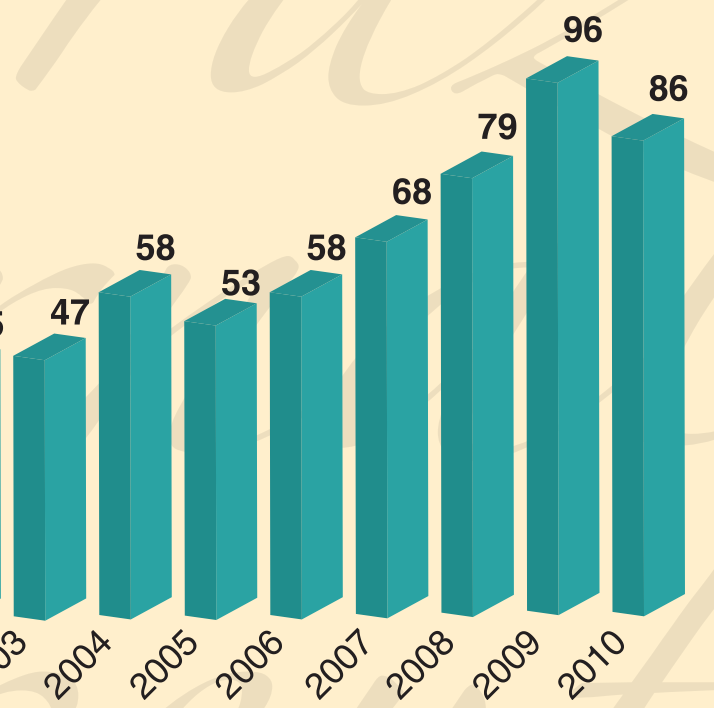

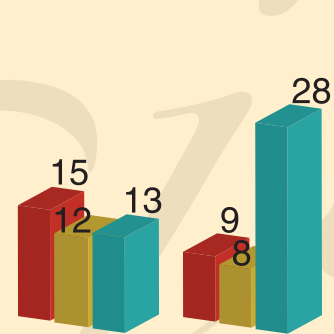

2001

2002

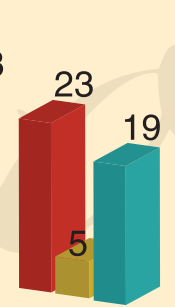

2003

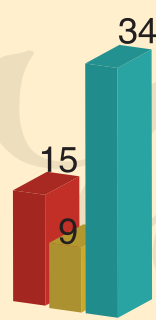

2004

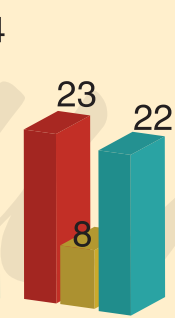

2005

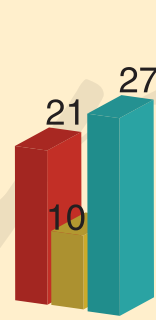

2006

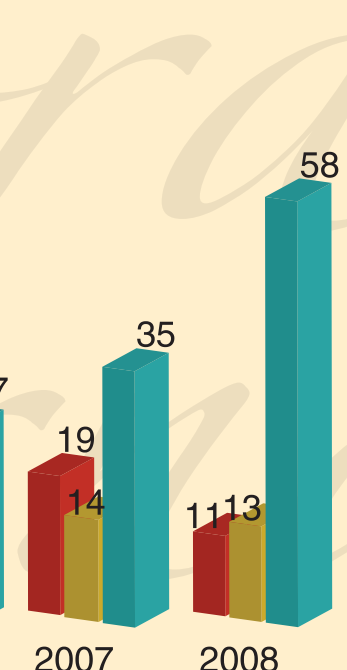

77

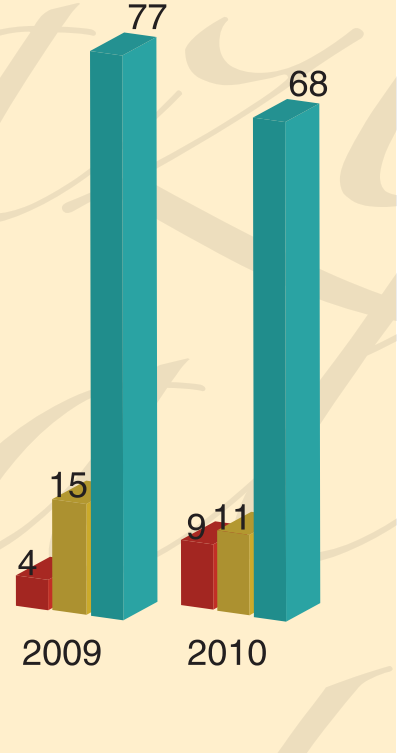

- Articles developed in the University of São Paulo

- Articles developed by the Univerisity of São Paulo with other Institutions

- Articles developed by afield Institutions (national and international) 


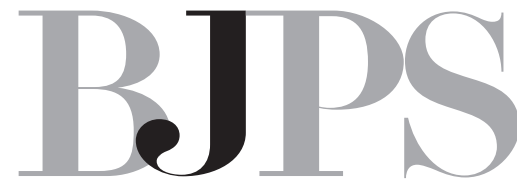

Brazilian Journal of Pharmaceutical Sciences

BRAZILIAN JOURNAL OF

PHARMACEUTICAL SCIENCES

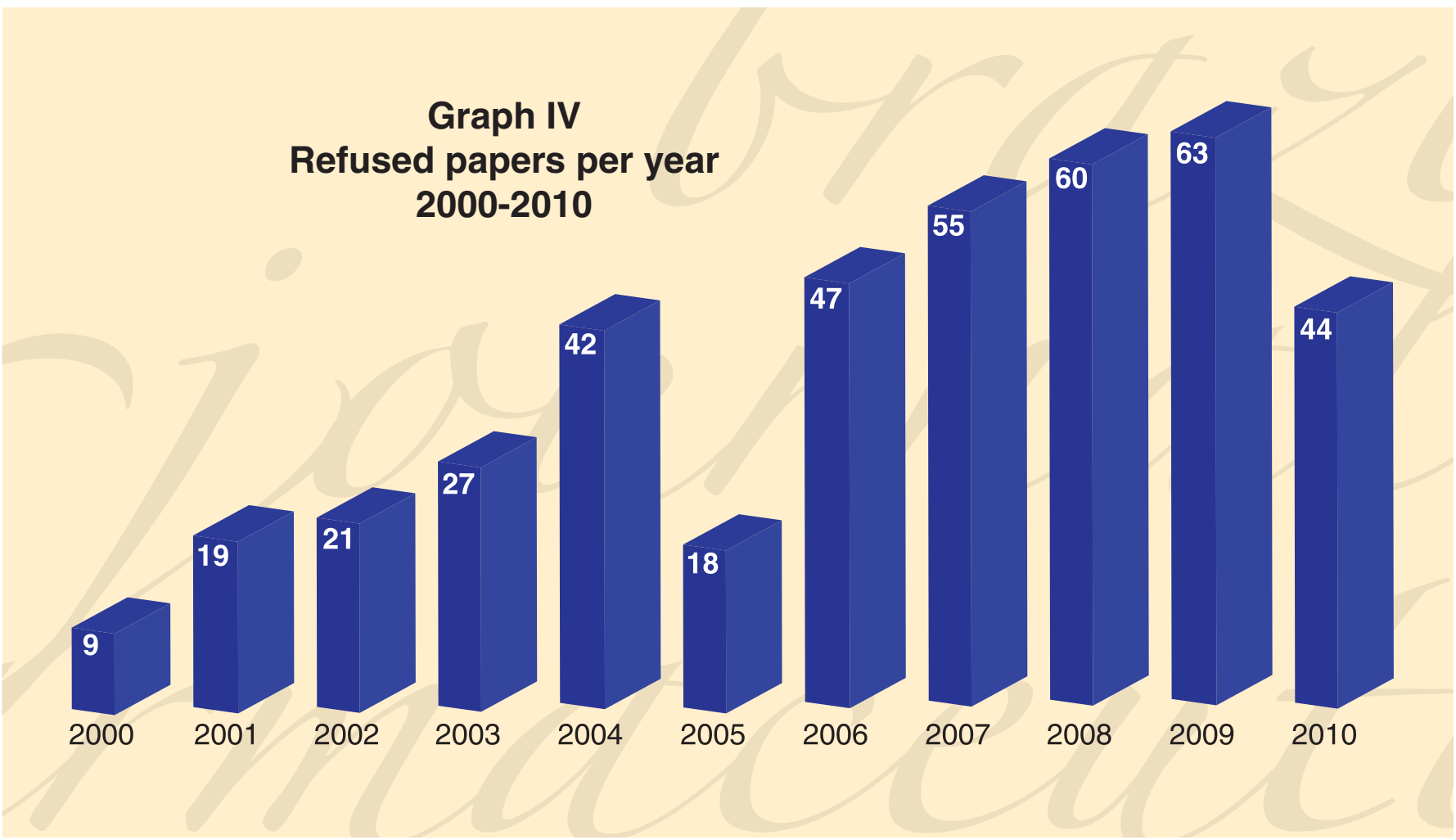

\section{REFERENCES}

COMISSÃO DE CREDENCIAMENTO. Programa de Apoio às Publicações Científicas Periódicas da USP. Available at: $<$ http://www.sibi.usp.br/credenciamento/regimento.htm>. Accessed on: 27 jun.2011.

JOURNAL CITATION REPORTS. Available at: <http://apps.webofknowledge.com/CitationReport.do?product=UA\&search mode=CitationReport\&SID=Y1PbLPmKAf5IHdbj6Eo\&page=1\&cr_pqid=1\&viewType=summary $>$. Accessed on: 28 jun . 2011.

MARQUES, F. Escreva bem ou pereça. Pesquisa FAPESP, abr., p.34-39, 2011.

ORTELLADO, P.; MACHADO, J. A. Direitos autorais e o acesso às publicações científicas. Revista ADUSP, ago., p.6-15, 2006.

OLIVEIRA, P. M. C. Porque o BJP não está na página da SBF? Boletim SBF, n.16, 2010. Available at: <http://www.sbf1.sbfisica. org.br/boletim1/mgs.236.htm>. Acessed on: 28 jun. 2011.

SALINAS, S. R. A. Associação entre a springer e o Brazilian Journal of Physics. Boletim SBF, n.10, 2010. Available at: $<\mathrm{http} / / /$ www.sbf1.sbfisica.org.br/boletim1/mgs.201htm>. Acessed on: 16 jun. 2010. 